\title{
BENDING ANALYSIS OF COMPOSITE AND SANDWICH BEAMS USING RITZ METHOD
}

\section{Armağan KARAMANLI *}

Department of Mechatronics, Faculty of Engineering and Architecture, İstanbul Gelişim University, 34215, İstanbul, Turkey

\begin{abstract}
In the present paper, the bending behaviour of laminated composite and sandwich beams subjected to various sets of boundary conditions which are simply supported (SS), clamped-simply supported (CS), clamped-clamped (CC) and clampedfree $(\mathrm{CF})$ are investigated by using the Timoshenko beam theory and the Ritz method. In order to solve the problem, the shape functions for axial, transverse deflections and the rotation of the cross-section are presented in polynomial forms. The validation and convergence studies are performed by solving symmetric and anti-symmetric cross-ply composite beam problems with various boundary conditions and aspect ratios by adding auxiliary functions to the shape functions. The results in terms of mid-span deflections, axial and shear stresses are compared with those from previous studies to validate the accuracy of the present study. The effects of fiber angle, lay-up and aspect ratio on displacements and stresses are studied.
\end{abstract}

Keywords: Composite Beam, Bending, Ritz Method, Timoshenko Beam Theory

\section{INTRODUCTION}

In recent years, with the advance of the production technology for the composite materials, the use of composite beam structures has been increasing because of new demands in aerospace, marine, automotive, and civil engineering applications. Due to the attractive properties in strength, stiffness and lightness, various beam theories have been developed to understand the mechanical behavior of these structures during the last decade. In [1], the review of these theories can be found.

The kinematics, strain and stress relations of a beam can be represented by using various beam theories. These theories can be divided into three following categories: the Euler Bernoulli Beam Theory (EBT), the Timoshenko Beam Theory (TBT) and the Reddy-Bickford Beam Theory (RBT). Since the effect of the transverse shear deformation neglected in the EBT, it is only suitable for thin beams-. TBT overcomes this adverse by taking into account the shear deformation effect. However, the TBT requires the shear correction factor (SCF) to compensate the error due to the assumption of the constant transverse shear strain and shear stress through the beam thickness. The SCF depends on the geometric and material parameters of the beam but the loading and boundary conditions are also important to determine the SCF [2-3]. On the other hand, TBT cannot satisfy the zero traction boundary conditions on the top and bottom surfaces of the beam. Many higher order beam theories (HBT) including quasi-3D ones have been developed to study the bending behaviour of composite beams and only some of them [4-14] are referenced here. HBT does not require a shear correction factor, satisfies the zero traction boundary conditions and importantly allows having better prediction of static, dynamic and buckling responses of composite beams.

Analytical and numerical methods have been used to investigate the flexural behaviour of composite and sandwich beams. The finite element methods (FEMs) are the most popular ones for the analysis of composite beams [15-28]. There are few studies related to the flexure analysis of laminated composite and sandwich beams by employing a meshless method [29-33]. As an analytical approach, the Navier solution is the simplest one which can be used only for the solution of the problems with simply supported (SS) boundary condition [34-36]. In order to deal with arbitrary end conditions, many 
different methods have been developed. The most commonly used one is the Ritz method [37-41]. A critical review of literature regarding to the bending, buckling and free vibration of laminated composite and sandwich beams is given in [42].

As it is seen from the literature survey above, the studies related to flexure analysis of the laminated composite and sandwich beams by employing Ritz method are still limited. In [1], the trigonometric series solutions are presented for the static, buckling and free vibration responses of laminated composite beams. The vibration analysis of cross-ply laminated beams subjected to different sets of boundary conditions based on a three-degree-of-freedom shear deformable beam theory via Ritz method is presented in [37]. By using the same shear deformation theory given in [37], the vibration, buckling and thermal buckling of laminated composite beams are investigated in [38-40]. An analytical solution for the buckling and free vibration analysis of laminated beams by using a Quasi3D theory and the Ritz method is given in [41]. Since the Ritz approach consists in permitting the analysis of any combination of boundary conditions, it is efficient to deal with static, buckling and vibration problems of composite beams. Furthermore, no restrictions on the stacking sequences exist, so that realistic configurations characterized by the presence of membrane and/or flexural anisotropy can be accounted for. The main scope of this work is to investigate the bending behaviour of the laminated composite and sandwich beams based on Timoshenko Beam Theory (TBT) by using Ritz method with polynomial shape functions. In the present paper, the static analysis of the laminated composite and sandwich beams are presented by considering various fiber angles, lay-ups, aspect ratios and sets of boundary conditions.

\section{THEORY AND FORMULATION}

In Figure 1, a laminated composite beam which is made of many plies of orthotropic materials in different orientations with respect to $\mathrm{x}$-axis is presented. It is assumed that a lamina has no gaps or empty spaces, behaves like a linear elastic material and is bounded perfectly to each other.

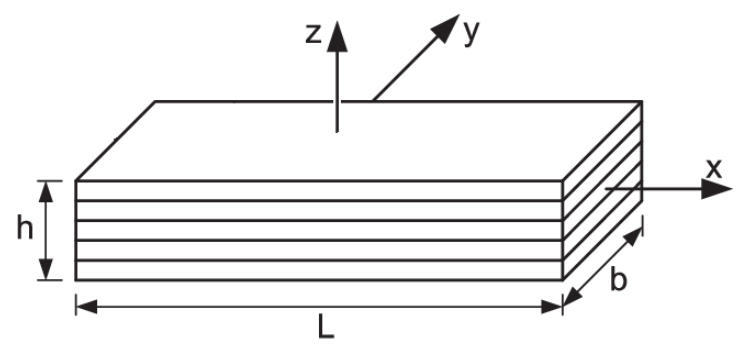

Figure 1. Geometry of a laminated composite beam

Where $\mathrm{h}$ is the height of the beam, $\mathrm{b}$ is the width and $\mathrm{L}$ is the length. The stress-strain relationship of the $\mathrm{k}^{\text {th }}$ orthotropic lamina in the material coordinate axes is given by [5]:

$$
\left\{\begin{array}{l}
\sigma_{x x} \\
\sigma_{x z}
\end{array}\right\}^{k}=\left[\begin{array}{cc}
Q_{11} & 0 \\
0 & Q_{55}
\end{array}\right]^{k}\left\{\begin{array}{l}
\varepsilon_{x x} \\
\gamma_{x z}
\end{array}\right\}
$$

where $\left(\sigma_{x x}, \sigma_{x z}\right)$ are the axial and shear stresses and $\left(\varepsilon_{x x}, \gamma_{x z}\right)$ are the axial strain and shear strain, respectively with respect to the laminate axes. $Q_{i j}$ 's are the transformed elastic constants or stiffness matrix with respect to laminate axis $\mathrm{x}$. The transformed elastic constants can be given by [8]:

$$
\begin{aligned}
& Q_{11}=C_{11} \cos ^{4} \theta+2\left(C_{12}+2 C_{66}\right) \cos ^{2} \theta \sin ^{2} \theta+C_{22} \sin ^{4} \theta \\
& Q_{55}=C_{44} \sin ^{2} \theta+C_{55} \cos ^{2} \theta
\end{aligned}
$$


Where

$$
C_{11}=\frac{E_{1}}{1-v_{12} v_{21}} ; C_{12}=\frac{E_{1} v_{21}}{1-v_{12} v_{21}} ; C_{22}=\frac{E_{2}}{1-v_{12} v_{21}} ; C_{66}=G_{12} ; C_{55}=G_{13} ; C_{44}=G_{23} ;
$$

$E_{1}, E_{2}, G_{12}, G_{13}, G_{23}, v_{12}$ and $v_{21}$ are the six independent engineering constants. E is the Young's Modulus, $\mathrm{G}$ is the Shear Modulus and $v$ is the Poisson's ratio.

To describe the TBT, the following coordinate system is introduced. The $\mathrm{x}$-coordinate is taken along the axis of the beam and the $\mathrm{z}$-coordinate is taken through the height (thickness) of the beam. In the general beam theory, all the loads and the displacements $(\mathrm{u}, \mathrm{w}, \phi)$ along the coordinates $(\mathrm{x}, \mathrm{z})$ are only the functions of the $\mathrm{x}$ and $\mathrm{z}$ coordinates.

The following displacement field is given for the TBT [5],

$$
\begin{aligned}
U(x, z) & =u(x)+z \phi(x) \\
W(x, z) & =w(x)
\end{aligned}
$$

Here $u$ and $w$ are the axial and transverse displacements of any point on the neutral axis, $\phi$ is the rotation of the cross sections. The non zero strains can be given as

$$
\begin{aligned}
& \varepsilon_{x x}=\frac{d U}{d x}=\frac{d u}{d x}+z \frac{d \phi}{d x} \\
& \gamma_{x z}=\frac{d U}{d z}+\frac{d W}{d x}=\phi+\frac{d w}{d x}
\end{aligned}
$$

The strain energy of the beam including the energy associated with the shearing strain can be written as,

$$
U=\frac{1}{2} \int_{V}\left(\sigma_{x x} \varepsilon_{x x}+\sigma_{x z} \gamma_{x z}\right) d V
$$

where $V$ is the volume of the beam. By substituting Eqs. (1) and (4) into Eq. (5), the strain energy can be obtained:

$$
U=\frac{1}{2} \int_{V}\left[Q_{11}\left\{\left(\frac{d u}{d x}\right)^{2}+z^{2}\left(\frac{d \phi}{d x}\right)^{2}+2 z \frac{d u}{d x} \frac{d \phi}{d x}\right\}+Q_{55} \kappa_{s}\left\{\phi^{2}+\left(\frac{d w}{d x}\right)^{2}+2 \phi \frac{d w}{d x}\right\}\right] d V
$$

where $\kappa_{S}$ is the shear correction factor to be used to compensate the error caused by the assumption of a constant transverse shear stress distribution along the beam thickness. The potential energy of the load $\mathrm{q}(\mathrm{x})$ is given by

$$
V=-\int_{-L / 2}^{L / 2} q w d x
$$

The stiffness coefficients can be introduced as follows: 


$$
\begin{gathered}
(A, B, D)=b \int_{-h / 2}^{+h / 2} Q_{11}\left(1, z, z^{2}\right) d z \\
A_{s}=b \int_{-h / 2}^{+h / 2} Q_{55} d z
\end{gathered}
$$

By using Eqs. 6 to 9, the total potential energy (П) can be written:

$$
\begin{gathered}
\Pi=U+V \\
\Pi=\frac{1}{2} \int_{-L / 2}^{L / 2}\left[A\left(\frac{d u}{d x}\right)^{2}+D\left(\frac{d \phi}{d x}\right)^{2}+2 B \frac{d u}{d x} \frac{d \phi}{d x}+\kappa_{s} A_{s} \phi^{2}+\kappa_{s} A_{s}\left(\frac{d w}{d x}\right)^{2}+2 \kappa_{s} A_{s} \phi \frac{d w}{d x}-2 q w\right] d x
\end{gathered}
$$

The mid-span deflections, axial and shear stresses are obtained by using the Ritz method. The Ritz method is based on variational statements such as priciples of virtual displacements or the principle of the minimum potential energy, which are equivalent to the governing equations as well as the natural boundary conditions. The displacement functions $u(\mathrm{x}), \mathrm{w}(\mathrm{x})$ and the rotation of the cross section $\phi(x)$ are presented by using the following polynomial series which satisfy the kinematic boundary conditions given in Table 1 ,

$$
\begin{array}{ll}
u(x)=\sum_{j=1}^{m} a_{j} \theta_{j}(x), & \theta_{j}(x)=\left(x+\frac{L}{2}\right)^{p_{u}}\left(x-\frac{L}{2}\right)^{q_{u}} x^{j-1} \\
w(x)=\sum_{j=1}^{m} b_{j} \varphi_{j}(x), & \varphi_{j}(x)=\left(x+\frac{L}{2}\right)^{p_{w}}\left(x-\frac{L}{2}\right)^{q_{w}} x^{j-1} \\
\phi(x)=\sum_{j=1}^{m} c_{j} \psi_{j}(x), & \psi_{j}(x)=\left(x+\frac{L}{2}\right)^{p_{\phi}}\left(x-\frac{L}{2}\right)^{q_{\phi}} x^{j-1}
\end{array}
$$

where $a_{j}, b_{j}$ and $c_{j}$ are unknown values to be determined, $\theta_{j}(x), \varphi_{j}(x)$ and $\psi_{j}(x)$ are the shape functions which are proposed for the boundary conditions (BC) to be studied within this paper, $p_{\xi}$ and $q_{\xi}(\xi=u, w, \phi)$ are the boundary exponents of auxiliary functions related with the boundary conditions given in Table 2. It has to be mentioned that the shape functions which do not satisfy the boundary conditions may cause slow convergence rates and numerical instabilities.

Table 1. Kinematic boundary conditions used for the numerical computations

\begin{tabular}{ccc}
\hline BC & $\mathbf{x}=-\mathbf{L} / \mathbf{2}$ & $\mathbf{x}=\mathbf{L} / \mathbf{2}$ \\
\hline $\mathrm{S}-\mathrm{S}$ & $\mathrm{u}=0, \mathrm{w}=0$ & $\mathrm{w}=0$ \\
\hline $\mathrm{C}-\mathrm{S}$ & $\mathrm{u}=0, \mathrm{w}=0, \phi=0, \mathrm{w}^{\prime}=0$ & $\mathrm{w}=0$ \\
\hline $\mathrm{C}-\mathrm{C}$ & $\mathrm{u}=0, \mathrm{w}=0, \phi=0, \mathrm{w}^{\prime}=0$ & $\mathrm{u}=0, \mathrm{w}=0, \phi=0, \mathrm{w}^{\prime}=0$ \\
\hline $\mathrm{C}-\mathrm{F}$ & $\mathrm{u}=0, \mathrm{w}=0, \phi=0, \mathrm{w}^{\prime}=0$ & \\
\hline
\end{tabular}

Table 2. Boundary exponents for various boundary conditions

\begin{tabular}{ccccccc}
\hline \multirow{2}{*}{ BC } & \multicolumn{1}{c}{ Left end } & \multicolumn{2}{c}{ Right end } \\
\cline { 2 - 6 } & $\boldsymbol{p}_{\boldsymbol{u}}$ & $\boldsymbol{p}_{\boldsymbol{w}}$ & $\boldsymbol{p}_{\boldsymbol{\phi}}$ & $\boldsymbol{q}_{\boldsymbol{u}}$ & $\boldsymbol{q}_{\boldsymbol{w}}$ & $\boldsymbol{q}_{\boldsymbol{\phi}}$ \\
\hline $\mathrm{SS}$ & 1 & 1 & 0 & 0 & 1 & 0 \\
\hline $\mathrm{CS}$ & 1 & 1 & 1 & 0 & 1 & 0 \\
\hline $\mathrm{CC}$ & 1 & 1 & 1 & 1 & 0 & 0 \\
\hline $\mathrm{CF}$ & 1 & 1 & 1 & 0 & 0 \\
\hline
\end{tabular}


One can substitute Eq. (11) into Eq. (10) and then use the principle of the minimum potential energy given by Eq. (12) to obtain the system of equations and determine the values of $a_{j}, b_{j}$ and $c_{j}$. As the number of parameters $(\mathrm{m})$ is increased, the approximate solution converges to the true solution of the problem.

$$
\frac{\partial \Pi}{\partial a_{j}}=0, \quad \frac{\partial \Pi}{\partial b_{j}}=0, \quad \frac{\partial \Pi}{\partial c_{j}}=0, \quad j=1,2,3, \ldots, m
$$

\section{NUMERICAL RESULTS}

This section is dedicated to understand the flexure behaviour of the composite beams based on the TBT formulation and Ritz method. The computed results which are obtained by employing different number of terms in the polynomial series expansions are used for convergence and verification studies. The results are presented in terms of displacements and stresses of composite beams considering various lay-ups, aspect ratios and boundary conditions. The results from previous studies $[5,8]$ in terms of dimensionless mid-span deflections, axial and shear stresses are used for comparison purposes. Three different aspect ratios (L/h) 5, 10 and 50 are considered. The shear correction factor is set to 5/6. The material properties of the problems studied within this paper are given in Table 3 .

The following non-dimensional quantities are used for the representation of the results;

Non-dimensional maximum transverse deflection of the beam:

$$
\bar{w}=\frac{100 E_{m} b h^{3}}{q_{0} L^{4}} w(0, z)
$$

Non-dimensional axial and shear stresses of the beam:

$$
\begin{aligned}
\bar{\sigma}_{x} & =\frac{b h^{2}}{q_{0} L^{2}} \sigma_{x}(0, z) \\
\bar{\sigma}_{x z} & =\frac{b h}{q_{0} L} \sigma_{x z}\left(-\frac{L}{2}, z\right)
\end{aligned}
$$

Table 3. Material properties of composite and sandwich beams

\begin{tabular}{cll}
\hline Problem & Structure & \multicolumn{1}{c}{ Material Properties } \\
\hline \multirow{2}{*}{1} & Type A & $\mathrm{E}_{1} / \mathrm{E}_{2}=25 ; \mathrm{E}_{3}=\mathrm{E}_{2} ; \mathrm{G}_{12}=\mathrm{G}_{13}=0.5 \mathrm{E}_{2} ; \mathrm{G}_{23}=0.2 \mathrm{E}_{2}$ \\
& $\mathrm{v}_{12}=\mathrm{v}_{13}=\mathrm{v}_{23}=0.25$ \\
\hline \multirow{3}{*}{2} & Face Layer: Type A \\
\cline { 2 - 3 } & Type B & Core Layer: \\
& $\mathrm{E}_{1} / \mathrm{E}_{2}=1 ; \mathrm{E}_{3}=\mathrm{E}_{2} ; \mathrm{G}_{12}=\mathrm{G}_{13}=1.5 \mathrm{E}_{2} ; \mathrm{G}_{23}=0.4 \mathrm{E}_{2}$ \\
& $\mathrm{v}_{12}=\mathrm{v}_{13}=\mathrm{v}_{23}=0.25$ \\
&
\end{tabular}

\subsection{Verification, Comparison and Convergence Studies}

The developed code is verified by solving symmetric and anti-symmetric cross-ply composite beams subjected to uniformly distributed load with various boundary conditions (SS, CF, CC and CS) and aspect ratios with respect to the different series number $m$.

The results in terms of non-dimensional mid-span deflections, axial and shear stresses are given in Tables 4-5 along with the results from previous studies. It is clear that the results obtained by using the Ritz method agree completely with those of previous papers [5,8]. It is found that for the static analysis, the responses converge quickly for all types of boundary conditions when $\mathrm{m}$ is set to 4 as it is seen from Tables 4 and 5. For the sake of accuracy, the extensive studies are performed by employing the series number $m$ as 6 . 
Karamanlı / Anadolu Univ. J. of Sci. and Technology A-Appl. Sci. and Eng. 19 (1)-2018

Table 4. Verification and convergence studies, dimensionless mid-span deflections for different number of terms.

\begin{tabular}{|c|c|c|c|c|c|c|c|}
\hline \multirow{2}{*}{ Theory } & \multirow{2}{*}{ Reference } & \multicolumn{3}{|c|}{ Symmetric $\left(0^{\circ} / 90^{\circ} / 0^{\circ}\right)$} & \multicolumn{3}{|c|}{ Anti-symmetric $\left(0^{\circ} / 90^{\circ}\right)$} \\
\hline & & $L / h=5$ & 10 & $\mathbf{5 0}$ & $L / h=5$ & 10 & $\mathbf{5 0}$ \\
\hline a. & Simply Supported Beams (S-S) & & & & & & \\
\hline TBT & Khdeir and Reddy [5] & 2.146 & 1.021 & 0.661 & 5.036 & 3.750 & 3.339 \\
\hline \multirow{4}{*}{ TBT } & 2 terms & 2.0171 & 0.8921 & 0.5321 & 4.3716 & 3.0858 & 2.6744 \\
\hline & 4 terms & 2.1464 & 1.0214 & 0.6614 & 5.0359 & 3.7502 & 3.3387 \\
\hline & 6 terms & 2.1464 & 1.0214 & 0.6614 & 5.0359 & 3.7502 & 3.3387 \\
\hline & 8 terms & 2.1464 & 1.0214 & 0.6614 & 5.0359 & 3.7502 & 3.3387 \\
\hline b. & Cantilever Beams (C-F) & & & & & & \\
\hline TBT & Khdeir and Reddy [5] & 6.698 & 3.323 & 2.243 & 16.436 & 12.579 & 11.345 \\
\hline \multirow{4}{*}{ TBT } & 2 terms & 6.5018 & 2.9700 & 1.2103 & 14.5143 & 8.9728 & 5.5320 \\
\hline & 4 terms & 6.6978 & 3.3228 & 2.2428 & 16.4362 & 12.5791 & 11.3448 \\
\hline & 6 terms & 6.6978 & 3.3228 & 2.2428 & 16.4362 & 12.5791 & 11.3448 \\
\hline & 8 terms & 6.6978 & 3.3228 & 2.2428 & 16.4362 & 12.5791 & 11.3448 \\
\hline c. & Cantilever Beams (C-C) & & & & & & \\
\hline TBT & Khdeir and Reddy [5] & 1.629 & 0.504 & 0.144 & 2.379 & 1.093 & 0.681 \\
\hline \multirow{4}{*}{ TBT } & 2 terms & 1.6005 & 0.4675 & 0.0412 & 2.1834 & 0.7756 & 0.0543 \\
\hline & 4 terms & 1.6293 & 0.5043 & 0.1443 & 2.3786 & 1.0929 & 0.6815 \\
\hline & 6 terms & 1.6293 & 0.5043 & 0.1443 & 2.3786 & 1.0929 & 0.6815 \\
\hline & 8 terms & 1.6293 & 0.5043 & 0.1443 & 2.3786 & 1.0929 & 0.6815 \\
\hline \multirow{2}{*}{$\begin{array}{c}\text { d. } \\
\text { TBT }\end{array}$} & Cantilever Beams (C-S) & & & & & & \\
\hline & Khdeir and Reddy [5] & 1.922 & 0.693 & 0.276 & 3.320 & 1.834 & 1.349 \\
\hline \multirow{4}{*}{ TBT } & 2 terms & 1.7923 & 0.5638 & 0.1471 & 2.6554 & 1.1701 & 0.6847 \\
\hline & 4 terms & 1.9216 & 0.6931 & 0.2764 & 3.3197 & 1.8345 & 1.3490 \\
\hline & 6 terms & 1.9216 & 0.6931 & 0.2764 & 3.3197 & 1.8345 & 1.3490 \\
\hline & 8 terms & 1.9216 & 0.6931 & 0.2764 & 3.3197 & 1.8345 & 1.3490 \\
\hline
\end{tabular}

Table 5. Verification and convergence studies, dimensionless axial $\bar{\sigma}_{x}\left(0, \frac{h}{2}\right)$ and shear $\bar{\sigma}_{x z}\left(-\frac{L}{2}, 0\right)$ stresses of S-S beams for different number of terms

\begin{tabular}{|c|c|c|c|c|c|c|c|}
\hline \multirow{2}{*}{ Theory } & \multirow{2}{*}{ Reference } & \multicolumn{3}{|c|}{ Symmetric $\left(0^{\circ} / 90^{\circ} / 0^{\circ}\right)$} & \multicolumn{3}{|c|}{ Anti-symmetric $\left(0^{\circ} / 90^{\circ}\right)$} \\
\hline & & $L / h=5$ & 10 & $\mathbf{5 0}$ & $L / h=5$ & 10 & 50 \\
\hline a. & Axial (Normal) Stress & & & & & & \\
\hline TBT & Zenkour [8] & 0.7776 & 0.7776 & 0.7776 & 0.2336 & 0.2336 & 0.2336 \\
\hline \multirow{4}{*}{ TBT } & 2 terms & 0.5184 & 0.5184 & 0.5184 & 0.1557 & 0.1557 & 0.1557 \\
\hline & 4 terms & 0.7776 & 0.7776 & 0.7776 & 0.2336 & 0.2336 & 0.2336 \\
\hline & 6 terms & 0.7776 & 0.7776 & 0.7776 & 0.2336 & 0.2336 & 0.2336 \\
\hline & 8 terms & 0.7776 & 0.7776 & 0.7776 & 0.2336 & 0.2336 & 0.2336 \\
\hline b. & Shear Stress & & & & & & \\
\hline TBT & Zenkour [8] & 0.2994 & 0.2994 & 0.2994 & 0.8553 & 0.8553 & 0.8553 \\
\hline \multirow{4}{*}{ TBT } & 2 terms & 0.3000 & 0.3000 & 0.3000 & 0.8571 & 0.8571 & 0.8571 \\
\hline & 4 terms & 0.3000 & 0.3000 & 0.3000 & 0.8571 & 0.8571 & 0.8571 \\
\hline & 6 terms & 0.3000 & 0.3000 & 0.3000 & 0.8571 & 0.8571 & 0.8571 \\
\hline & 8 terms & 0.3000 & 0.3000 & 0.3000 & 0.8571 & 0.8571 & 0.8571 \\
\hline
\end{tabular}

\subsection{Bending Analysis of Laminated Composite and Sandwich Beams}

Four different boundary conditions, SS, CS, CC and CF are considered respectively for the bending analysis of laminated composite and sandwich beams subjected to uniformly distributed load. The mid-span deflections, axial and shear stresses are computed based on the TBT theories, lay-ups, fiber angles and aspect ratios.

\subsubsection{Laminated Composite Beams: Type A}

The symmetric $\left[0^{\circ} / \theta / 0^{\circ}\right]$ and un-symmetric $\left[0^{\circ} / \theta\right]$ composite beams are considered. In Tables 6 and 7 , variations of mid-span displacements, axial and shear stresses respect to the fiber angle $(\theta)$ are given. 
As the fiber angle increases, mid-span deflections and maximum axial stress values increase for all type of boundary conditions and aspect ratios.

As the aspect ratio increases the mid-span deflection decreases. One can easily observe that the axial and shear stresses remain same as the aspect ratio increases. It is clear that from Figures 2 and 3, as the fiber angle increases, the dimensionless axial and shear stresses increase for all type of boundary conditions and aspect ratios. The discontinuities are visible for all types of composite beam structures.

Table 6. Dimensionless mid-span deflections of $\left[0^{\circ} / \theta / 0^{\circ}\right]$ and $\left[0^{\circ} / \theta\right]$ beams for various boundary conditions under a uniformly distributed load, Type A.

\begin{tabular}{|c|c|c|c|c|c|c|c|c|c|c|}
\hline $\begin{array}{r}\text { A } \\
\text { Rat }\end{array}$ & $\begin{array}{l}\text { pect } \\
\text { o(L/h) }\end{array}$ & Theory & Lay-ups & $0^{\circ}$ & $15^{\circ}$ & $30^{\circ}$ & $45^{\circ}$ & $60^{\circ}$ & $75^{\circ}$ & $90^{\circ}$ \\
\hline \multicolumn{11}{|c|}{ a. $\quad$ Simply supported beams (S-S) } \\
\hline \multirow{2}{*}{\multicolumn{2}{|c|}{5}} & \multirow{6}{*}{ TBT } & {$\left[0^{\circ} / \theta\right]$} & 1.8234 & 1.8910 & 2.1276 & 2.6757 & 3.7836 & 4.8467 & 5.0359 \\
\hline & & & {$\left[0^{\circ} / \theta / 0^{\circ}\right]$} & 1.8234 & 1.8426 & 1.8964 & 1.9737 & 2.0566 & 2.1216 & 2.1464 \\
\hline \multirow{2}{*}{\multicolumn{2}{|c|}{10}} & & {$\left[0^{\circ} / \theta\right]$} & 0.9234 & 0.9726 & 1.1547 & 1.6169 & 2.6223 & 3.5968 & 3.7502 \\
\hline & & & {$\left[0^{\circ} / \theta / 0^{\circ}\right]$} & 0.9234 & 0.9304 & 0.9490 & 0.9737 & 0.9978 & 1.0151 & 1.0214 \\
\hline \multirow{2}{*}{\multicolumn{2}{|c|}{50}} & & {$\left[0^{\circ} / \theta\right]$} & 0.6354 & 0.6787 & 0.8433 & 1.2780 & 2.2507 & 3.1969 & 3.3387 \\
\hline & & & {$\left[0^{\circ} / \theta / 0^{\circ}\right]$} & 0.6354 & 0.6385 & 0.6458 & 0.6537 & 0.6590 & 0.6610 & 0.6614 \\
\hline \multicolumn{11}{|c|}{ b. $\quad$ Clamped simply supported beams (C-S) } \\
\hline \multirow{2}{*}{\multicolumn{2}{|c|}{ בת }} & \multirow{6}{*}{ TBT } & {$[0 \%]$} & 1.5899 & 1.6371 & 1.7929 & 2.1135 & 2.6811 & 3.2070 & 3.3197 \\
\hline & & & {$\left[0^{\circ} / \theta / 0^{\circ}\right]$} & 1.5899 & 1.6087 & 1.6623 & 1.7409 & 1.8269 & 1.8953 & 1.9216 \\
\hline \multirow{2}{*}{\multicolumn{2}{|c|}{10}} & & {$[0 \%$} & 0.5983 & 0.6229 & 0.7107 & 0.9194 & 1.3500 & 1.7637 & 1.8345 \\
\hline & & & {$\left[0^{\circ} / \theta / 0^{\circ}\right]$} & 0.5983 & 0.6041 & 0.6203 & 0.6432 & 0.6674 & 0.6860 & 0.6931 \\
\hline \multirow{2}{*}{\multicolumn{2}{|c|}{50}} & & {$\left[0^{\circ} / \theta\right]$} & 0.2636 & 0.2811 & 0.3475 & 0.5223 & 0.9125 & 1.2919 & 1.3490 \\
\hline & & & {$\left[0^{\circ} / \theta / 0^{\circ}\right]$} & 0.2636 & 0.2649 & 0.2683 & 0.2720 & 0.2747 & 0.2760 & 0.2764 \\
\hline \multicolumn{11}{|c|}{ Cantilever beams (C-F) } \\
\hline \multirow{2}{*}{\multicolumn{2}{|c|}{5}} & \multirow{6}{*}{ TBT } & {$\left[0^{\circ} / \theta\right]$} & 5.7197 & 5.9398 & 6.7150 & 8.5326 & 12.2449 & 15.8121 & 16.4363 \\
\hline & & & {$\left[0^{\circ} / \theta / 0^{\circ}\right]$} & 5.7197 & 5.7783 & 5.9424 & 6.1774 & 6.4278 & 6.6232 & 6.6978 \\
\hline \multirow{2}{*}{\multicolumn{2}{|c|}{10}} & & {$[0 \% / \theta]$} & 3.0197 & 3.1844 & 3.7961 & 5.3561 & 8.7611 & 12.0626 & 12.5791 \\
\hline & & & {$\left[0^{\circ} / \theta / 0^{\circ}\right]$} & 3.0197 & 3.0416 & 3.1002 & 3.1774 & 3.2513 & 3.3038 & 3.3228 \\
\hline \multirow{2}{*}{\multicolumn{2}{|c|}{50}} & & {$\left[0^{\circ} / \theta\right]$} & 2.1557 & 2.3027 & 2.8621 & 4.3397 & 7.6462 & 10.8628 & 11.3448 \\
\hline & & & {$\left[0^{\circ} / \theta / 0^{\circ}\right]$} & 2.1557 & 2.1659 & 2.1908 & 2.2174 & 2.2348 & 2.2416 & 2.2428 \\
\hline \multicolumn{11}{|c|}{ Clamped clamped beams (C-C) } \\
\hline \multirow{2}{*}{\multicolumn{2}{|c|}{5}} & \multirow{6}{*}{ TBT } & {$\left[0^{\circ} / \theta\right]$} & 1.3247 & 1.3579 & 1.4634 & 1.6645 & 1.9954 & 2.3025 & 2.3786 \\
\hline & & & {$\left[0^{\circ} / \theta / 0^{\circ}\right]$} & 1.3247 & 1.3416 & 1.3898 & 1.4614 & 1.5407 & 1.6046 & 1.6293 \\
\hline \multirow{2}{*}{\multicolumn{2}{|c|}{10}} & & {$[0 \% / \theta]$} & 0.4247 & 0.4394 & 0.4904 & 0.6057 & 0.8341 & 1.0527 & 1.0929 \\
\hline & & & {$\left[0^{\circ} / \theta / 0^{\circ}\right]$} & 0.4247 & 0.4293 & 0.4424 & 0.4614 & 0.4819 & 0.4981 & 0.5043 \\
\hline \multirow{2}{*}{\multicolumn{2}{|c|}{50}} & & {$[0 \% / \theta]$} & 0.1367 & 0.1455 & 0.1790 & 0.2669 & 0.4625 & 0.6527 & 0.6815 \\
\hline & & & {$\left[0^{\circ} / \theta / 0^{\circ}\right]$} & 0.1367 & 0.1374 & 0.1393 & 0.1414 & 0.1431 & 0.1440 & 0.1443 \\
\hline
\end{tabular}

Table 7. Dimensionless axial $\bar{\sigma}_{x}\left(0, \frac{h}{2}\right)$ and shear $\bar{\sigma}_{x z}\left(-\frac{L}{2}, 0\right)$ stresses of $\left[0^{\circ} / \theta / 0^{\circ}\right]$ and $\left[0^{\circ} / \theta\right] \mathrm{S}-\mathrm{S}$ beams under a uniformly distributed load, Type A.

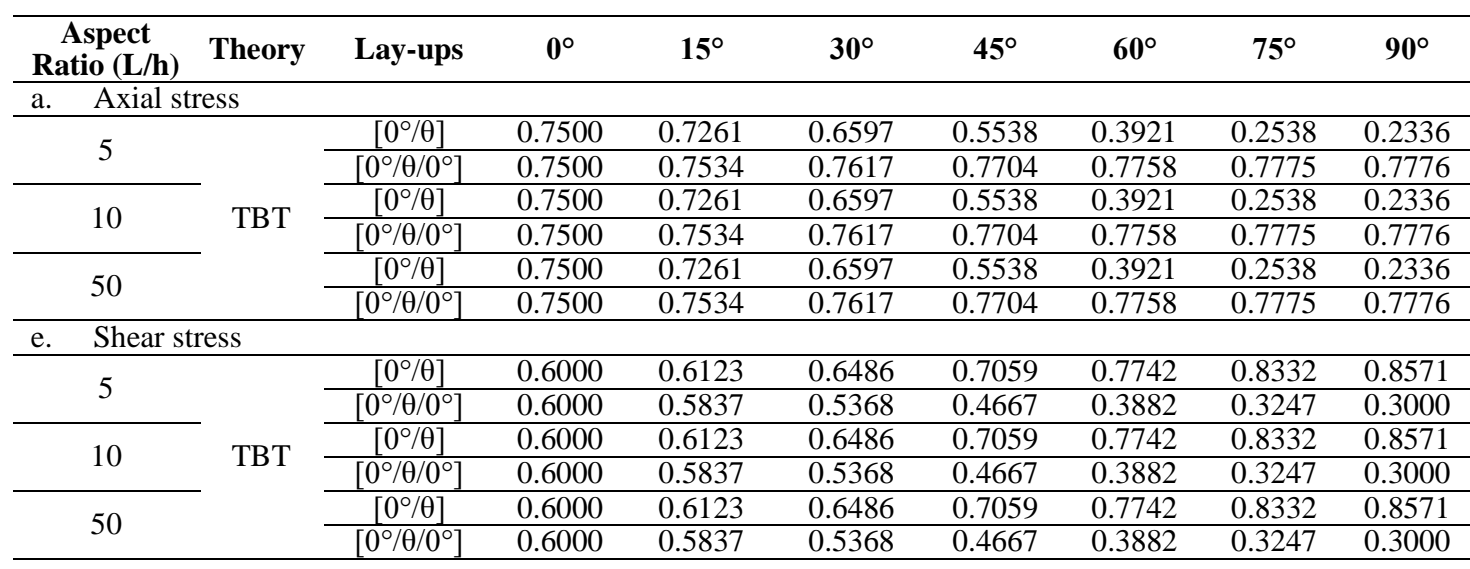




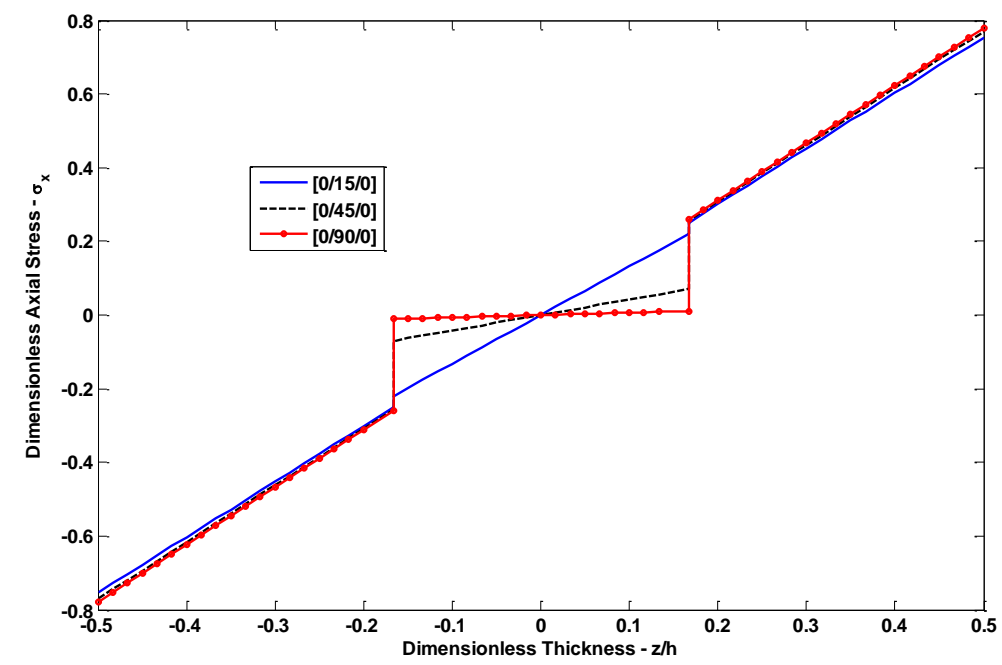

a. Symmetric lay-up

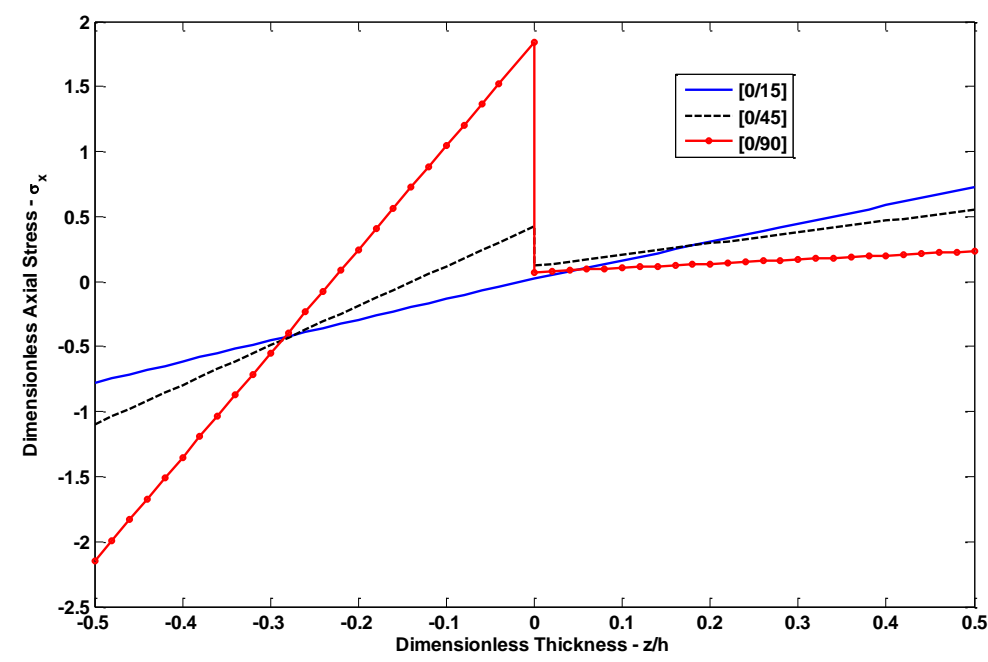

b. Anti-symmetric lay-up

Figure 2. Axial stress distribution through the thickness of symmetric and anti-symmetric beams with S-S boundary condition based on TBT, Type A, L/h=5.

\subsubsection{Laminated Composite Sandwich Beams: Type B}

In this example, the elasto-static analysis of cross-ply sandwich beams (Type B) under uniformly distributed load with the top and bottom face thickness $\left(\mathrm{h}_{1}\right)$ and core thickness $\left(\mathrm{h}_{2}\right)$ are studied. Based on the various thickness and aspect ratios, the dimensionless mid-span deflections and stresses are presented by using Ritz method in Tables 8 and 9. It is clear that the dimensionless mid-span deflections increase as the thickness ratio increases.

The dimensionless axial and shear stress variations through thickness of the sandwich beams are plotted in Figure 4 for different thickness ratios. It is found that the stresses increase as the thickness ratio changes from 3 to 8 . The maximum dimensionless axial and shear stresses are obtained for the thickness value at 8 . 
Karamanlı / Anadolu Univ. J. of Sci. and Technology A-Appl. Sci. and Eng. 19 (1)-2018

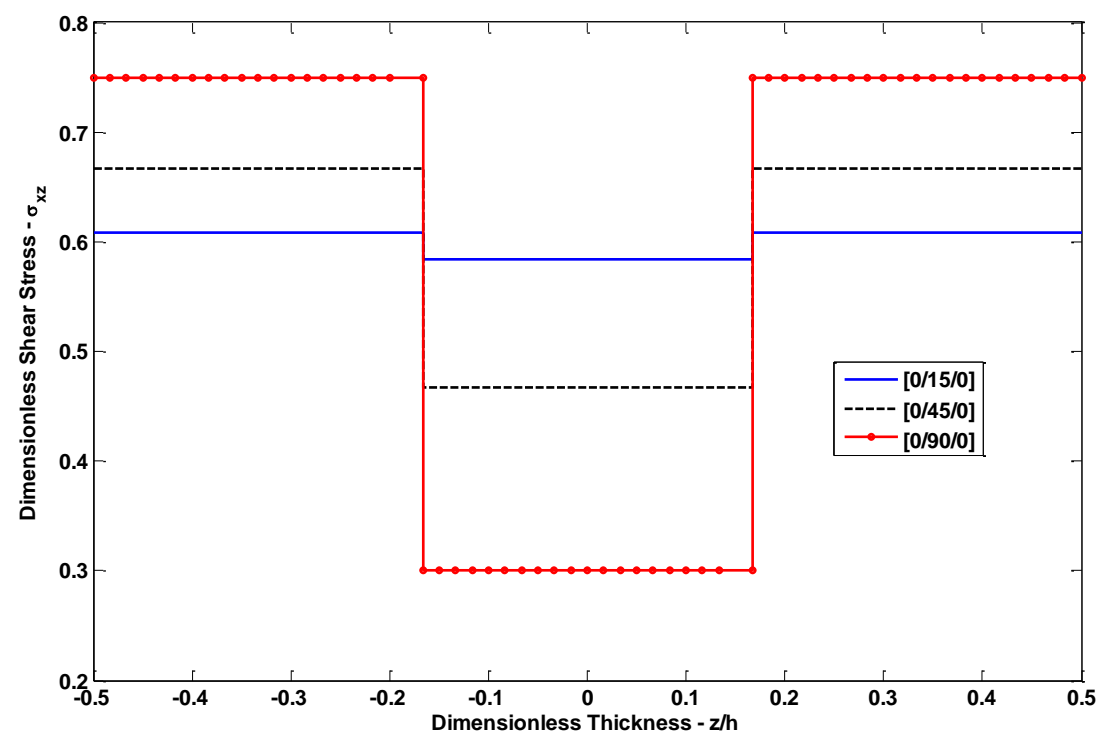

a. Symmetric lay-up

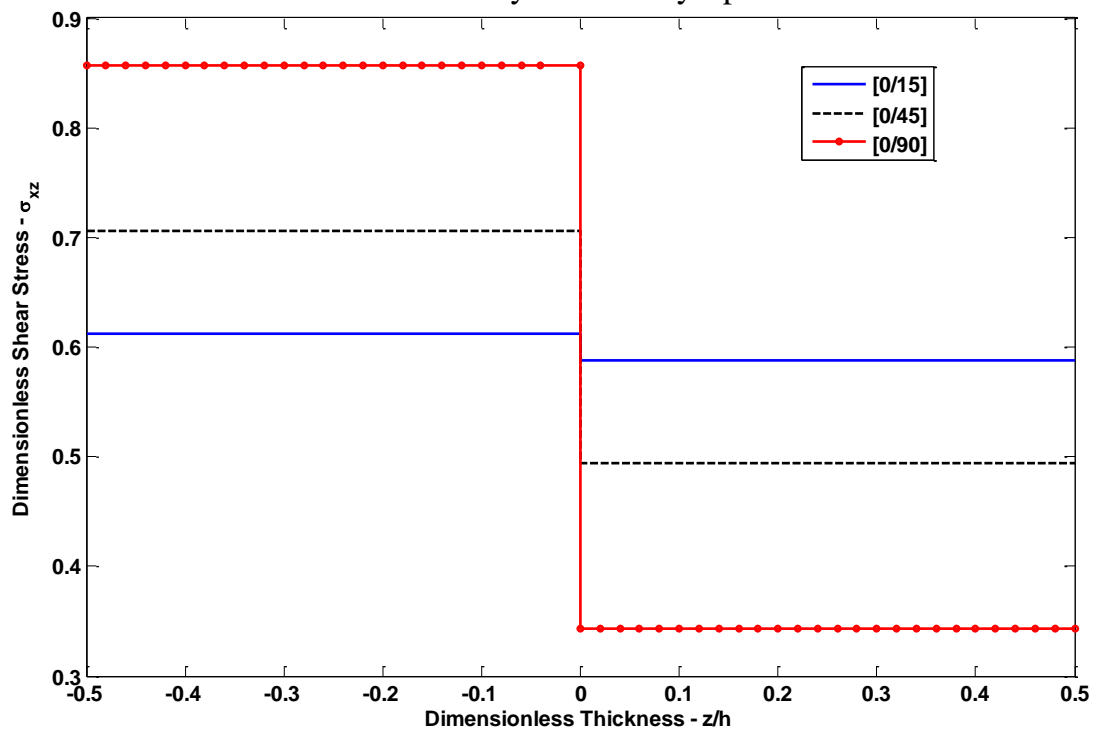

b. Anti-symmetric lay-up

Figure 3. Shear stress distribution through the thickness of symmetric and anti-symmetric beams with S-S boundary condition based on TBT, Type A, L/h=5.

Table 8. Dimensionless mid-span deflections of $\left[0^{\circ} / 90^{\circ} / 0^{\circ}\right]$ beams for various boundary conditions under a uniformly distributed load, Type B.

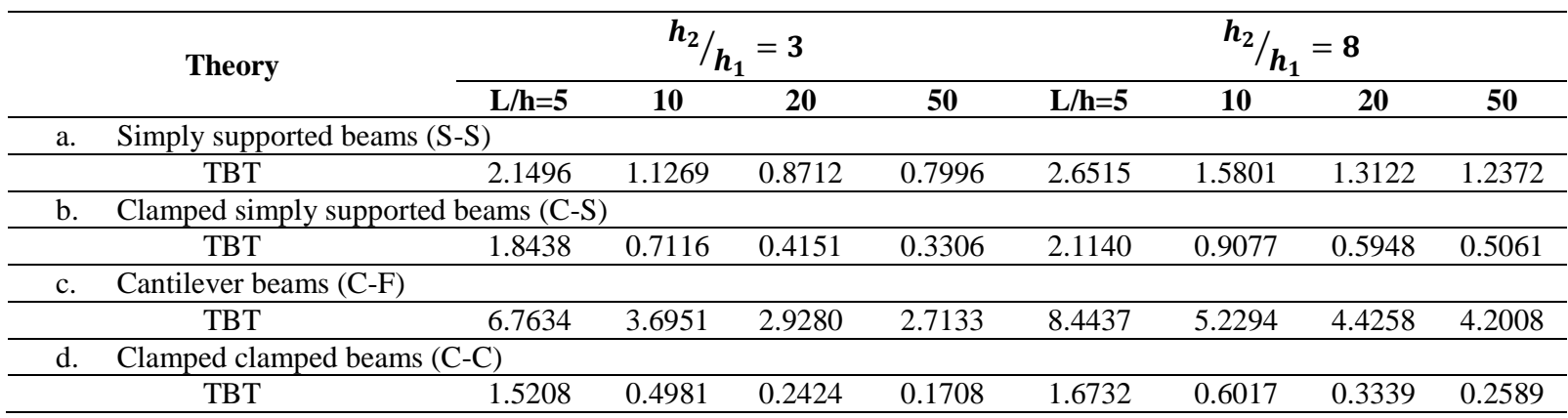


Karamanlı / Anadolu Univ. J. of Sci. and Technology A-Appl. Sci. and Eng. 19 (1)-2018

Table 9. Dimensionless axial $\bar{\sigma}_{x}\left(0, \frac{h}{2}\right)$ and shear $\bar{\sigma}_{x z}\left(-\frac{L}{2}, 0\right)$ stresses of $\left[0^{\circ} / 90^{\circ} / 0^{\circ}\right] \mathrm{S}-\mathrm{S}$ beams under a uniformly distributed load, Type B.

\begin{tabular}{cccccccccc}
\hline \multirow{2}{*}{ Theory } & \multicolumn{4}{c}{$\boldsymbol{h}_{\mathbf{2}} / \boldsymbol{h}_{\mathbf{1}}=\mathbf{3}$} & & \multicolumn{4}{c}{$\boldsymbol{h}_{\mathbf{2}} \boldsymbol{h}_{\mathbf{1}}=\mathbf{8}$} \\
\cline { 2 - 10 } & $\mathbf{L} / \mathbf{h}=\mathbf{5}$ & $\mathbf{1 0}$ & $\mathbf{2 0}$ & $\mathbf{5 0}$ & $\mathbf{L} / \mathbf{h}=\mathbf{5}$ & $\mathbf{1 0}$ & $\mathbf{2 0}$ & $\mathbf{5 0}$ \\
\hline a. & Axial stress & & & & & & \\
\hline TBT & 0.9455 & 0.9455 & 0.9455 & 0.9455 & 1.4712 & 1.4712 & 1.4712 & 1.4712 \\
\hline b. Shear stress & & & & & & & & \\
\hline TBT & 0.5455 & 0.5455 & 0.5455 & 0.5455 & 0.5714 & 0.5714 & 0.5714 & 0.5714 \\
\hline
\end{tabular}

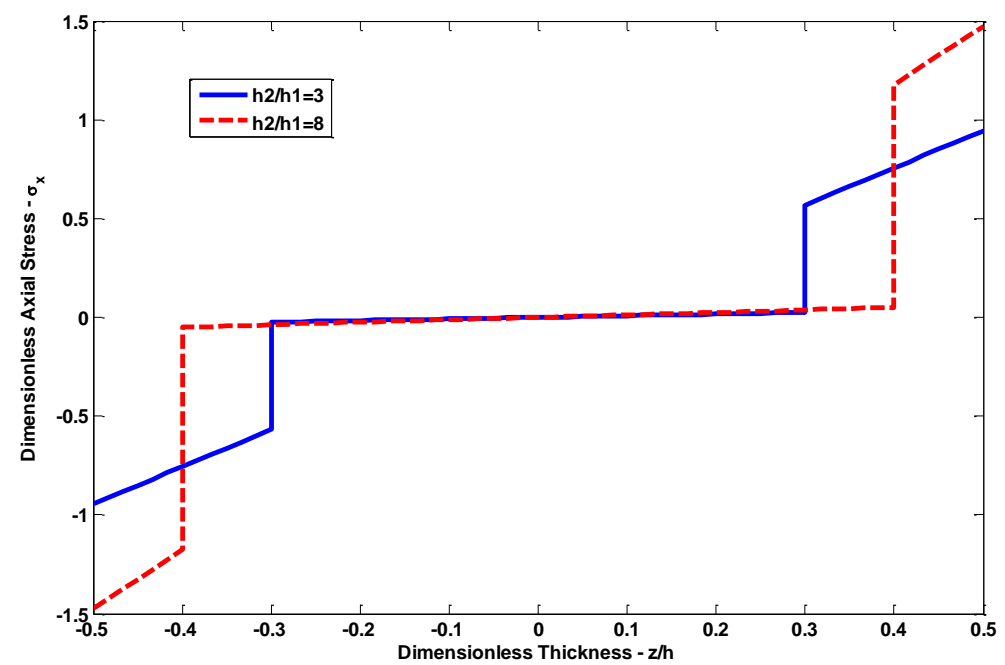

a. Axial Stress

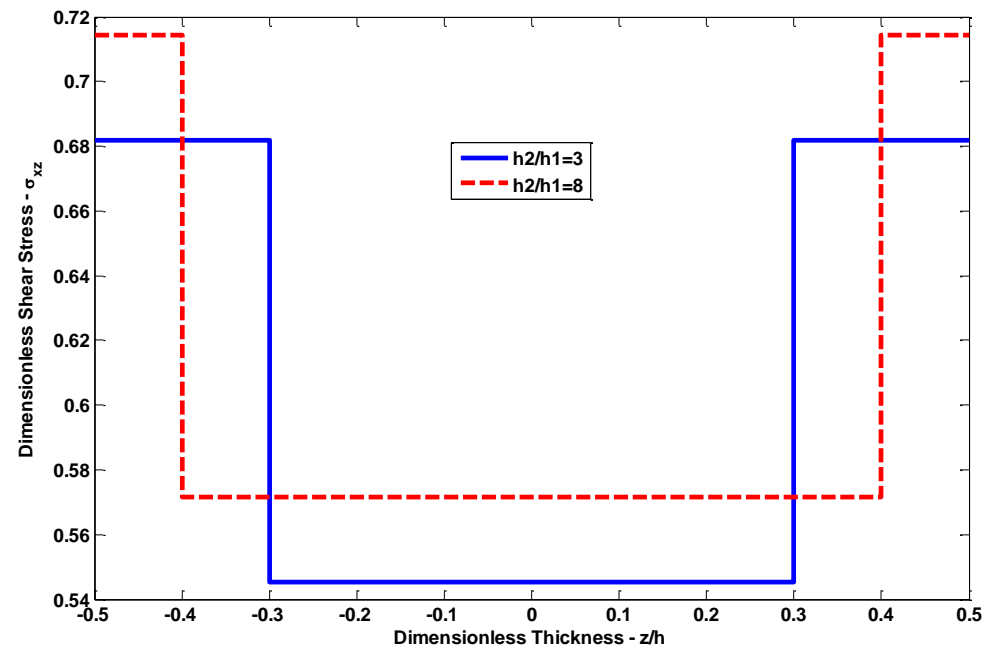

b. Shear Stress

Figure 4. Axial and shear stress distribution through the thickness of symmetric sandwich beams with $\mathrm{S}-\mathrm{S}$ boundary condition based on TBT, Type B, L/h=5.

\section{CONCLUSION}

The polynomial series solution for the flexure behaviour of the laminated composite and sandwich beams using TBT formulation and Ritz method is presented. Various composite and sandwich beam configurations are considered based on different aspect ratios, lay-ups, fiber angles and boundary conditions. The shape functions for axial and transverse deflections and the rotation of the cross 
sections are assumed to be in polynomial forms to obtain the approximate solution. The computed results are compared with the calculations obtained by other authors.

The following results can be drawn from the computed results based on the TBT:

- Since the all coupling effects from material vanish for the fiber angle value $0^{\circ}$, the axial displacement u cannot be obtained.

- Flexural behaviour of the laminated composite beams can be controlled to meet the desired goals by choosing suitable fiber angle.

- Regarding to the anti-symmetric laminated composite beams (Type A), the importance of the shear effect increases while the fiber angle increases for all type of boundary conditions.

- The fiber angles has a significant effect on the mid-span deflections, axial and shear stresses of the symmetric and anti-symmetric laminated composite beams (Type A) for all type of boundary conditions and aspect ratios.

- It is explicit that the difference between the computed results in terms of mid-span deflections, axial and shear stresses for the symmetric and anti-symmetric laminated composite beams (Type A) increase as the fiber angle increases.

- It is worth noting that C-F laminated composite sandwich beam (Type B) is much more sensitive to the thickness ratio change than the other sandwich beam models.

- According to the analysis for S-S laminated composite sandwich beam (Type B), the difference in terms of axial stress values is larger than those of obtained by using shear stress values with respect to thickness ratio change.

It is found that using the Ritz method with polynomial shape functions including auxiliary functions is simple to implement, efficient and provides quick convergence rates and expected results for the static analysis of laminated composite and sandwich beams.

\section{REFERENCES}

[1] Nguyen TK, Nguyen ND, Vo TP, Thai HT. Trigonometric-series solution for analysis of laminated composite beams. Compos Struct 2017; 160:142-151.

[2] Timoshenko SP, Goodier JC. Theory of Elasticity. New York, NY, USA: McGraw-Hill Co. Inc., 1970.

[3] Wang CM, Reddy JN, Lee, KH, Shear Deformable Beams and Plates Relations with Classical Solutions. Oxford: Elsevier Science Ltd., 2000.

[4] Kant T, Manjunath BS. Refined theories for composite and sandwich beams with C0 finite elements. Comput Struct 1989; 33(3):755-764.

[5] Khdeir AA, Reddy JN. An exact solution for the bending of thin and thick cross-ply laminated beams. Compos Struct 1997; 37(2):195-203.

[6] Soldatos KP, Watson P. A general theory for the accurate stress analysis of homogeneous and laminated composite beams. Int J Solids Struct 1997; 34(22): 2857-2885. 
[7] Shi G, Lam KY, Tay TE. On efficient finite element modeling of composite beams and plates using higher-order theories and an accurate composite beam element. Compos Struct 1998; 41(2):159-165.

[8] Zenkour AM. Transverse shear and normal deformation theory for bending analysis of laminated and sandwich elastic beams. Mechanics of Composite Materials \& Structures 1999; 6(3): 267283.

[9] Karama M, Afaq KS, Mistou S. Mechanical behaviour of laminated composite beam by the new multi-layered laminated composite structures model with transverse shear stress continuity. Int $\mathbf{J}$ Solids Struct 2003; 40(6):1525-1546.

[10] Murthy MVVS, Mahapatra DR, Badarinarayana K, Gopalakrishnan S. A refined higher order finite element for asymmetric composite beams. Compos Struct 2005; 67(1):27-35.

[11] Vidal P, Polit O. A family of sinus finite elements for the analysis of rectangular laminated beams. Compos Struct 2008; 84(1):56-72.

[12] Aguiar RM, Moleiro F, Soares CMM. Assessment of mixed and displacement-based models for static analysis of composite beams of different cross-sections. Compos Struct 2012; 94 (2):601616.

[13] Nallim LG, Oller S, Onate E, Flores FG. A hierarchical finite element for composite laminated beams using a refined zigzag theory. Compos Struct 2017; 163:168-184.

[14] Vo TP, Thai HT, Nguyen TK, Lanc D, Karamanli A. Flexural analysis of laminated composite and sandwich beams using a four-unknown shear and normal deformation theory. Compos Struct 2017; 176:388-397.

[15] Yuan FG, Miller RE. A higher order finite element for laminated beams. Compos Struct 1990; 14(2):125-50.

[16] Yu H. A higher-order finite element for analysis of composite laminated structures. Compos Struct 1994; 28(4):375-83.

[17] Chandrashekhara K, Bangera K. Free vibration of composite beams using a refined shear flexible beam element. Comput Struct 1992; 43(4):719-27.

[18] Marur S, Kant T. Free vibration analysis of fiber reinforced composite beams using higher order theories and finite element modelling. J Sound Vib 1996; 194(3):337-51.

[19] Karama M, Harb BA, Mistou S, Caperaa S. Bending, buckling and free vibration of laminated composite with a transverse shear stress continuity model. Compos B Eng 1998; 29(3):223-34.

[20] Shi G, Lam K, Tay T. On efficient finite element modeling of composite beams and plates using higher-order theories and an accurate composite beam element. Compos Struct 1998; 41(2):15965 .

[21] Shi G, Lam K. Finite element vibration analysis of composite beams based on higher-order beam theory. J Sound Vib 1999; 219(4):707-21. 
[22] Murthy M, Mahapatra DR, Badarinarayana K, Gopalakrishnan S. A refined higher order finite element for asymmetric composite beams. Compos Struct 2005; 67(1):27-35.

[23] Subramanian P. Dynamic analysis of laminated composite beams using higher order theories and finite elements. Compos Struct 2006;73(3):342-53.

[24] Vidal P, Polit O. A family of sinus finite elements for the analysis of rectangular laminated beams. Compos Struct 2008;84(1):56-72.

[25] Vo TP, Thai H-T. Static behavior of composite beams using various refined shear deformation theories. Compos Struct 2012;94(8):2513-22.

[26] Vo TP, Thai H-T. Vibration and buckling of composite beams using refined shear deformation theory. Int J Mech Sci 2012;62(1):67-76.

[27] Mantari J, Canales F. Finite element formulation of laminated beams with capability to model the thickness expansion. Compos B Eng 2016;101:107-15.

[28] Li J, Wu Z, Kong X, Li X, Wu W. Comparison of various shear deformation theories for free vibration of laminated composite beams with general lay-ups. Compos Struct 2014;108:767-78.

[29] Ferreira AJM, Roque CMC, Martins PALS. Radial basis functions and higher order shear deformation theories in the analysis of laminated composite beams and plates. Compos Struct 2004; 66:287-293.

[30] Ferreira AJM. Thick composite beam analysis using a global meshless approximation based on radial basis functions. Mech Adv Mater Struct 2003; 10:271-84.

[31] Roque CMC, Fidalgo DS, Ferreira AJM, Reddy JN. A study of a microstructure dependent composite laminated Timoshenko beam using a modified couple stress theory and a meshless method. Compos Struct 2013; 96:532-537.

[32] Liew KM, Lim HK, Tan MJ, He XQ. Analysis of laminated composite beams and plates with piezoelectric patches using the element-free Galerkin method. Computational Mechanics 2002; 29:486-497.

[33] Karamanli, A. Flexure Analysis of Laminated Composite and Sandwich Beams Using Timoshenko Beam Theory. (Submitted for publication).

[34] Matsunaga $\mathrm{H}$. Vibration and buckling of multilayered composite beams according to higher order deformation theories. J Sound Vib 2001; 246 (1):47-62.

[35] Mantari J, Canales F. A unified quasi-3D HSDT for the bending analysis of laminated beams. Aerosp Sci Technol 2016; 54:267-75.

[36] Kant T, Marur S, Rao G. Analytical solution to the dynamic analysis of laminated beams using higher order refined theory. Compos Struct 1997; 40 (1):1-9.

[37] Aydogdu M. Vibration analysis of cross-ply laminated beams with general boundary conditions by Ritz method. Int J Mech Sci 2005; 47(11): 1740-55. 
Karamanlı / Anadolu Univ. J. of Sci. and Technology A-Appl. Sci. and Eng. 19(1)-2018

[38] Aydogdu M. Buckling analysis of cross-ply laminated beams with general boundary conditions by Ritz method. Compos Sci Technol 2006; 66 (10):1248-55.

[39] Aydogdu M. Thermal buckling analysis of cross-ply laminated beams with general boundary conditions. Compos Sci Technol 2007; 67 (6):1096-1104.

[40] Aydogdu M. Free vibration analysis of angle-ply laminated beams with general boundary conditions. J Reinf Plast Compos 2006; 25(15):1571-83.

[41] Mantari J, Canales F. Free vibration and buckling of laminated beams via hybrid Ritz solution for various penalized boundary conditions. Compos Struct 2016; (152):306-315.

[42] Sayyad AS, Ghugal, YM. Bending, buckling and free vibration of laminated composite and sandwich beams: A critical review of literature. Compos Struct 2017; (171):486:504. 